\title{
ATUAÇÃO RESPONSÁVEL OU JOGO DE MERCADO? ENTENDENDO A RELAÇÃO EMPRESA-MÍDIA PARA A EFETIVAÇÃO DO CONSUMO SUSTENTÁVEL
}

\author{
IT IS A RESPONSIBLE ACTION OR A GAME OF MARKET? \\ UNDERSTANDING THE RELATION COMPANY-MEDIA FOR \\ THE REALIZATION OF SUSTAINABLE CONSUMPTION
}

Data de submissão: 08-11-2012 Aceite: 26-05-2013

Minelle Enéas da Silva ${ }^{1}$ Luis Felipe Machado Nascimento²

\section{RESUMO}

Quanto aos relacionamentos que podem ser observados entre diferentes stakeholders para atendimento de demandas da sociedade, percebem-se mudanças voltadas para o desenvolvimento sustentável, na busca por novas práticas de produção e consumo, atualmente insustentáveis. Com isso, assume-se a possibilidade de um novo contexto social, com ações responsáveis e voltadas para essa nova perspectiva. Assim sendo, o objetivo deste artigo é identificar qual a relação entre o Walmart Brasil e a mídia local para a efetivação do consumo sustentável no varejo de supermercados em Recife, Pernambuco, com base na marca Hiper Bompreço. Com caráter exploratório e abordagem qualitativa, esta pesquisa, conduzida sob a forma de um estudo de caso, considera o consumo sustentável como seu pano de fundo a fim de reconhecer relações entre os atores selecionados. A discussão realizada e as conclusões identificadas indicam a existência de atuação responsável em ambas as partes, mesmo considerando como possível o jogo de mercado, o que pode ser evidenciado a partir do poder de influência que empresa e mídia têm sobre o indivíduo-consumidor e os demais atores da sociedade.

Palavras-chave: Consumo sustentável; Mídia; Varejo; Stakeholders.

${ }^{1}$ Possui graduação em Administração pela Universidade Federal de Campina Grande - UFCG, mestrado em Administração pela Universidade Federal de Pernambuco - UFPE e doutorado em andamento em Administração pela Universidade Federal do Rio Grande do Sul - UFRGS. Porto Alegre. Rio Grande do Sul. Brasil. E-mail: minele.adm@gmail.com

${ }^{2}$ Possui graduação em Engenharia Elétrica pela Universidade Federal de Santa Maria - UFSM, mestrado em Engenharia de Produção pela Universidade Federal de Santa Maria -UFSM e Doutorado em Economia e Meio Ambiente pela UNIVERSITÄT GESAMTHOCHSCHULE KASSEL, Alemanha. Atualmente é professor na Escola de Administração da Universidade Federal do Rio Grande do Sul, UFRGS. Porto Alegre. Rio Grande do Sul. Brasil. E-mail: nascimentolf@gmail.com 


\section{ABSTRACT}

In the context of market analysis about the relationships that can be observed between different stakeholders to meet the demands of society, it is perceived as a real possibility to observe the changes aimed at sustainable development in the search for new practices of currently unsustainable production and consumption. Thus, we assume the possibility of a new social context, with responsible actions and focused on this new perspective. Thus, the article aims to identify the relationship between Wal-Mart Brazil and local media for the realization of sustainable consumption in retail supermarkets in Recife-PE, from the brand Hiper Bompreço. With focus exploratory and qualitative approach to research conducted in the form of a case study considers sustainable consumption as a background of search, to recognition of relations between the actors selected. The discussions held and the findings are suggestive of the existence of responsible action on both actors, even as possible considering the game market, which can be evidenced from the power of influence of company and media on the individual-consumer, and other actors society.

Keywords: Sustainable Consumption; Media; Retail; Stakeholders.

\section{INTRODUÇÃO}

Em sentido contrário à correnteza egoísta e individualista que cada vez mais amplia os impactos do ser humano na sociedade e no meio ambiente, realiza-se a discussão acerca do emergir de um novo paradigma de desenvolvimento, o sustentável. Nessa perspectiva, para que haja mudanças, argumenta-se que produção e consumo precisam estar relacionados e direcionados para novos padrões, baseados em práticas mais responsáveis (TUKKER et al., 2008), o que se apresenta como possível a partir de uma nova atuação de diferentes atores que incluem a empresa - que produz e distribui -, o governo - que pode regular -, a mídia - que informa -, os fornecedores - que intermediam a distribuição - e o indivíduo - que, considerado em toda a rede de interações identificada, deve assumir um papel voltado mais ao contexto coletivo.

A partir dessa discussão, sabe-se que a sociedade atual é uma sociedade de consumo, em que o consumismo continuamente é estimulado e voltado de forma míope para a satisfação de necessidades e desejos dos consumidores. Assim, como apresenta Lipovetsky (2007), percebe-se a existência de uma felicidade paradoxal, na medida em que o homo consumericus de uma sociedade emergente do hiperconsumo não considera as consequências de suas práticas insustentáveis. Por esse motivo, discute-se o consumo sustentável, que preconiza para sua efetivação a inter-relação entre diferentes atores sociais (stakeholders), voltada para o desenvolvimento sustentável (JACKSON, 2007; MICHAELIS, 2003; SILVA, 2012).

Para que se possam verificar essas interações a partir de uma rede de influências em determinado setor econômico, Michaelis (2003) argumenta que todos os atores sociais em seu campo de atuação devem contribuir para essa perspectiva sustentável, assumindo uma mudança em suas práticas. Dentre aqueles que podem contribuir para essa ideia, ainda segundo o autor, identifica-se a mídia, que, enquanto direcionador de opiniões, é capaz de gerar impactos nas ações da sociedade. O processo de comunicação entre mídia e empresa está condicionado aos níveis de troca de informações que estes podem gerar em sua atuação, já que as relações e consequências que são criadas influenciam toda a sociedade.

Assim, entendendo a necessidade de envolvimento entre os atores como condição sine qua non para a efetivação do consumo sustentável, parte-se do pressuposto de que uma empresa, para estar contribuindo com uma mudança em seu contexto de atuação, necessita dessas interações no desenvolvimento de suas atividades. Nesse sentido, ao observar a atual dinâmica empresarial, percebe-se que muitas organizações estão reestruturando suas atividades e adequando seus comportamentos às questões voltadas para o desenvolvimento sustentável, dentre as quais se destaca o Walmart Brasil, que, ao 
longo dos últimos anos, tem apresentado um conjunto de práticas mais responsáveis (GUNTHER, 2006).

Com o foco nessa empresa e em suas interações com outros atores, o objetivo deste artigo é identificar qual a relação entre o Walmart Brasil e a mídia local para a efetivação do consumo sustentável no varejo de supermercados em Recife, Pernambuco. Para tanto, optou-se pelo estudo do Hiper Bompreço, já que este possui relevância econômica para o nordeste brasileiro (WALMART BRASIL, 2010a). A discussão realizada pretende discorrer sobre o potencial impacto da comunicação sobre um novo contexto, convergindo as ações desenvolvidas pela empresa com as ações midiáticas, no sentido de identificar se tais ações ocorrem por meio de uma atuação responsável ou se estão apenas envolvidas em um jogo de mercado para dar continuidade à insustentável e atual sociedade de consumo.

Como forma de proporcionar uma melhor compreensão da proposta do estudo, este está dividido em quatro partes, além dessa introdutória. São apresentados, em um segundo momento, os aspectos teóricos norteadores da pesquisa para o entendimento do fenômeno em questão. Em seguida, visualizam-se os procedimentos metodológicos. Na quarta seção, são apresentados e discutidos os resultados da pesquisa, incluindo uma caracterização macro sobre a empresa e a identificação das interações direcionadas para o consumo sustentável e das relações da empresa com a mídia local. Além disso, como forma de reflexão sobre esses resultados, são apresentadas as considerações finais.

\section{DISCUSSÃO TEÓRICA}

Os debates envolvendo o desenvolvimento sustentável tornam cada vez mais evidente a necessidade de reestruturação do atual modelo utilizado, ao considerar que a visão coletivista deve ser priorizada em relação às características individualistas até então estimuladas (FOLADORI, 2005). Esse pensamento sugere que mudanças sociais devem ser realizadas para que seja possível obter os benefícios dessa nova prática. A ideia básica do desenvolvimento sustentável está relacionada com a tarefa de harmonização de dimensões fundamentais (social, econômica e ambiental) no sentido de atender às necessidades das gerações atuais sem comprometer a satisfação das necessidades das futuras gerações (ELKINGTON, 2001; SACHS, 2007; WCDE, 1987), o que corrobora a urgência de envolvimento coletivo.

Com essa concepção, entende-se que os diferentes stakeholders, que estão aptos a atuar em toda a sociedade de acordo com suas singularidades, devem desenvolver obrigações e práticas que possam auxiliar na efetivação dessa nova forma de desenvolvimento por meio da atuação mútua e complementar. Tal fato é trabalhado de modo concomitante com a abordagem do consumo sustentável, já que, para ocorrer, necessita dessa interação. Dentre os atores que podem ser aqui considerados, destaca-se a mídia como facilitadora para a disseminação de práticas responsáveis dos diferentes atores, incentivando um posicionamento social coletivo e estimulando a possibilidade de mudança no padrão de consumo utilizado. Nesse sentido, é necessário identificar as contribuições da mídia para o consumo sustentável.

\subsection{Consumo sustentável}

No contexto social, a mudança nas práticas de consumo "reflete o momento cultural a qual a sociedade está inserida, perante as dinâmicas e demandas requeridas, necessitando, assim, de um direcionamento coletivo para a efetivação de um desenvolvimento emergente, o sustentável" (SILVA, 2011, p. 29). Com isso, entende-se que, seguindo a ideia de mudança de paradigma e considerando-a viável, estão surgindo novas preocupações do consumidor, as quais mudam o foco individualista de seu consumo para uma visão mais ampla quanto aos impactos desse modo de agir (MICHAELIS, 2000). Vem à tona, diante disso, o movimento na sociedade por um consumo mais responsável (SANTOS et al., 2008). 
Para trabalhar com o padrão sustentável de consumo, não se devem observar apenas as ações desenvolvidas pelos consumidores, mas sim um conjunto de interações sociais a fim de obter uma perspectiva política do fenômeno. No entanto, ressalta-se a importância que o consumidor tem nesse processo, pois seu papel está relacionado a novos comportamentos de consumo consciente, caracterizado, conforme Silva e Gómez (2010), pela cultura vivenciada, pelo estilo de vida adotado, pelo poder aquisitivo, pelas questões éticas assumidas por cada um e pela educação que proporciona uma percepção sistemática da busca por um consumo mais consciente. Tais aspectos estão relacionados com o estudo do comportamento do consumidor e facilitam a definição estratégica empresarial quanto às práticas de marketing (SOLOMON, 2011).

Além disso, percebe-se que, segundo Jackson (2007), para que o consumo sustentável possa ser praticado, é necessária uma adequação dos padrões de consumo à nova realidade social, a partir da mudança no consumo de boa parte dos materiais e de um redirecionamento das práticas desenvolvidas. Esse consumo sustentável pode ser alcançado pelo compartilhamento de responsabilidades, em meio a uma nova atuação em todas as esferas - econômicas, sociais e políticas -, pressupondo, segundo Silva (2012), a existência de consciência individual e de alinhamento organizacional aos aspectos sociais e ambientais, além da atuação de outros atores na coordenação de práticas e relações na dinâmica do consumo sustentável. Para Jackson (2004), essa prática sustentável do consumo envolve não apenas consumir menos, mas também consumir diferente e eficientemente.

Assim, frente a esse contexto, diferentes atores necessitam assumir responsabilidades distintas, mas convergentes ao objetivo maior que envolve a reestruturação no paradigma de consumo utilizado. Nessa perspectiva, além das empresas que estão inseridas em diferentes estruturas e que possuem diferentes comportamentos no mercado, outros atores podem ser importantes: fornecedores, competidores, organizações do terceiro setor, instituições financiadoras, universidades, mídia, governo e indivíduos (dentro do contexto da comunidade) (MICHAELIS, 2000; 2003; MONT; PLEPYS, 2007; SILVA 2011), conforme demonstra a Figura 1, exposta a seguir.

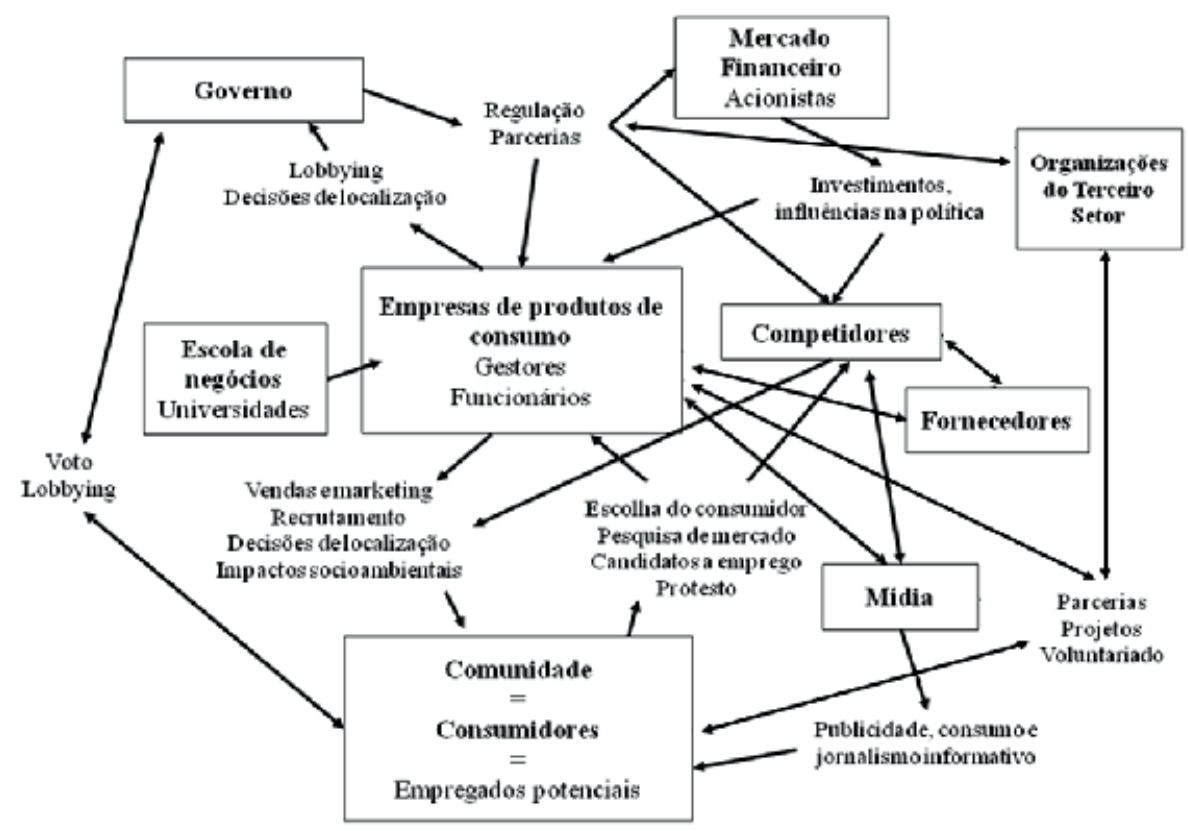

Figura 1: Mapa da rede de influências para o consumo sustentável Fonte: Silva (2011). 
A partir dessa ilustração, assume-se o foco nas empresas e em como estas podem contribuir para o consumo sustentável, a partir das interações com outros stakeholders. Em geral, a comunidade empresarial tem interpretado o consumo sustentável como o consumo de produtos sustentáveis ou ecologicamente corretos apenas. Todavia, o que se percebe é que existe uma complexidade maior que circunda a prática sustentável do consumo, motivo pelo qual se discute a ideia de interações sociais (MICHAELIS, 2003). Assim, nesse contexto, três dimensões devem ser consideradas quanto à atuação de uma empresa: (1) desenvolvimento de tecnologias e novas práticas; (2) mudança nos incentivos econômicos, já que, segundo o modelo de Michaelis (2003), as interações sociais são modificadas entorno da empresa; e (3) mudança cultural por parte da empresa em seu contexto de influências.

Málovics, Csigéné e Kraus (2008) corroboram essa ideia, indicando a possibilidade de atuação empresarial em direção a um consumo mais ou menos sustentável, a partir de seus comportamentos adotados. Baseando-se nessa perspectiva, Silva (2011) desenvolveu uma pesquisa na qual definiu um conjunto de variáveis que estão relacionadas a essa abordagem e que facilitam a identificação prática das ações empresariais quanto à sustentabilidade. Segundo o autor, devem ser analisados: eco-eficiência, práticas próprias de consumo, incentivos do governo, elos da cadeia de suprimentos, edição de escolha, cidadania corporativa, marketing responsável e diálogo com stakeholders - cada uma dessas categorias sendo desdobradas em diferentes critérios de análise.

Diante dessa visão, considera-se que, com essas mudanças tidas como complementares, as empresas, em meio a um conjunto de interações sociais, conseguem se adequar e se alinhar ao novo ambiente de atuação, facilitando, assim, sua contribuição ao mercado. Para o presente estudo, selecionou-se a variável diálogo com stakeholders, especificamente a relação com a mídia, a fim de identificar empiricamente quais são as contribuições e relações verificadas em dado setor econômico que permitem que a interação entre esses dois atores - empresa e mídia - seja mais bem-sucedida. Salienta-se que, mesmo com o foco nessa díade de atores, é necessário trabalhar a abordagem do consumo sustentável de forma macro, observando como ocorrem as interações entre os todos os atores.

\subsection{A ação midiática e o consumo sustentável}

Segundo Mendonça (2006), a mídia é considerada, genericamente, como todo discurso que pode ser mediado por tecnologias de comunicação e da informação para audiências ampliadas, ou seja, todo tipo de meio de comunicação que seja utilizado para passar informações para determinado público. Para Santos (2006), o papel da mídia relaciona-se com a reconfiguração simbólica de algumas questões na sociedade. Assim, de modo geral, a mídia reflete os modelos de pensamento e as questões que estão em ebulição social, seja por meios impressos ou digitais. Todavia, como Reisch, Spach e Bietz (2008) sugerem, a internet e a televisão conseguem influenciar a mudança nas práticas de consumo de uma população com mais eficácia, criando um pensamento diferenciado em seus interlocutores.

Considerada por muitos como a fonte de informação que mais facilita o entendimento das questões relacionadas ao meio ambiente, a mídia pode ser vista como um meio capaz de estimular uma concepção holística, envolvendo a natureza e os problemas sociais, sobre essa temática (SANTOS, 2006). Para Rossetti e Giacomini Filho (2010, p. 155) a mídia pode ser utilizada para buscar um consenso social, que, caso tenha foco em questões de sustentabilidade, pode delinear novo pensamento coletivo. Segundo os autores, "não se trata de um consenso absoluto e universal em que toda a sociedade está em acordo, mas de consensos estabelecidos por pessoas, grupos, comunidades e setores da sociedade em determinados momentos, segundo determinados interesses e de forma dinâmica e dialógica".

No entanto, embora se entenda que existem boas iniciativas no que se refere a tornar visíveis as ações e práticas que podem ser desenvolvidas ou que estão sendo realizadas, o discur- 
so midiático traz uma vertente preocupante, "já que se fala de um filtro através do qual a sociedade interpreta e confere sentido aos acontecimentos" (SANTOS, 2005, p. 229). Ainda segundo a autora, isso se relaciona ao modo de selecionar, editar e relatar determinados discursos para a sociedade, o que faz diferença na assimilação de fatos e conceitos. Para que haja a possibilidade de um padrão sustentável de consumo, segundo Santos (2005, p. 231):

É fundamental que o consumo sustentável integre a pauta midiática e, como ela, faça parte das discussões desta esfera pública abstrata, já que o ato comunicacional constitui e legitima um espaço de articulação social em que percepções e valores são processados e ressignificados em sua dinâmica.

Para Santos (2010, p. 4), "a mesma mídia que incentiva o aumento do consumo também abre espaço para a possibilidade de uma nova mentalidade social, por meio de propagandas institucionais [...] que defendem o uso sustentável dos recursos disponíveis". Portanto, considerando que esse ator é capaz de impactar diretamente na construção de opinião da sociedade, à medida que se insere na discussão sobre o consumo sustentável, estimulando novas práticas em diferentes âmbitos, tem a capacidade de construir um novo significado para as relações de consumo existentes no mercado. Portanto, como destacado anteriormente, caso assuma um papel responsável na rede de influências de determinado setor, a mídia pode contribuir para a efetivação dessa abordagem sobre o consumo.

Discute-se que, usualmente, a mídia ignora os impactos socioambientais causados pelas empresas, já que, "de um lado, os jornais apontam as lacunas e os movimentos do jogo de poder; do outro, ignoram, em seu discurso, as idiossincrasias das políticas públicas (no âmbito socioambiental) em torno das articulações entre os poderes político e econômico" (SANTOS, 2006, p. 5). Deve-se buscar, assim, uma comunicação responsável tanto por parte desse discurso midiático como por parte da empresa, indicando o que ela faz e como ela educa a sociedade, a fim de gerar respostas às necessidades imediatas e futuras dos consumidores e do ecossistema (KRUGLIANSKAS; ALIGRERI; ALIGRERI, 2009).

Segundo Rossetti e Giacomini Filho (2010, p. 168), não se "chegou a um consenso social sobre o consumo sustentável, mas este se aloja numa nova correlação de forças amparadas em avanços consensuais favoráveis às causas ambientais, que seria uma contínua terceira via que não despreza a racionalidade em suas ponderações". Ressalta, ainda, que o atual conceito, em construção, é originário de um processo consensual conduzido por organizações, pessoas e sistemas de comunicação. Assim, para que haja uma maior disseminação dessas informações para toda a sociedade, segundo Kruglianskas, Aligreri e Aligreri (2009), é preciso atribuir um caráter responsável a esses discursos. Para tanto, discute-se ser necessário considerar os relatórios sociais ou de sustentabilidade, as notícias investigativas que demonstrem atuações de empresas, as notícias educativas e as informações positivas pertinentes para a comunicação tanto da pauta midiática como da perspectiva mercadológica de uma organização.

\section{PROCEDIMENTOS METODOLÓGICOS}

Com o objetivo de identificar a relação entre o Walmart Brasil e a mídia local para a efetivação do consumo sustentável no varejo de supermercados em Recife, Pernambuco, ao focar o discurso da empresa, este estudo assume um caráter exploratório para melhor reconhecimento do contexto argumentativo-teórico e das características pertinentes ao setor analisado (CRESWELL, 2010). Para isso, o desenvolvimento desta pesquisa ocorre com base em uma abordagem qualitativa - na medida em que se busca entender a efetivação de dada relação (OLIVEIRA, 2005) -, conduzida sob a forma de um estudo de caso - estratégia que favorece a visualização 
macro e micro do contexto analisado (GOLDENBERG, 2009).

A partir dessa perspectiva, para esta pesquisa, selecionou-se o estado de Pernambuco, que é a sede da empresa analisada na região nordeste. Nesse contexto, a seleção da marca Hiper Bompreço é relevante pela grande representatividade que possui quanto às estratégias socioambientais do Walmart Brasil, considerando que essa marca é uma das representantes do hipermercado que integram a empresa no contexto nacional.

O procedimento de coleta de dados envolveu a realização de entrevistas e o levantamento documental. Ressalta-se que o objetivo do trabalho está na relação existente entre a mídia e a empresa selecionada, motivo pelo qual se buscou identificar possíveis convergências.

Desse modo, participaram do processo de coleta de dados: o Diretor Nacional de Comunicação e a Gerente Regional (do nordeste) de Comunicação, que respondem diretamente por todas as práticas da empresa voltadas para a questão da sustentabilidade. Foram realizadas, ainda, observações em diferentes lojas, a fim de identificar como ocorre o processo comunicacional para disseminação de práticas junto aos funcionários. Além disso, foram analisados os Relatórios de Sustentabilidade e os dados levantados no website da empresa. Para compreender a possibilidade de atuação da mídia, buscou-se levantar notícias que tinham foco no setor de supermercados e na empresa a partir de pesquisa on-line com período intervalar de 2010 a 2011. Para tanto, foram selecionados os 20 links que tiveram maior destaque com as palavras-chave: Supermercado; Recife; Walmart; Sustentabilidade; e Hiper Bompreço.

Definiu-se como procedimento de análise a análise de conteúdo na perspectiva de Bardin (2009), ao entender que as informações contidas nas entrevistas realizadas e nos documentos e arquivos levantados contribuem para a compreensão da busca pelo consumo sustentável no setor, além da relação entre a mídia e a empresa nesse contexto. Vale ressaltar que, ao longo do processo de análise, buscou-se isenção principalmente no que se refere ao poder de manipulação das informações por qualquer uma das partes, com o intuito de melhor direcionar a pesquisa sob a perspectiva do desenvolvimento sustentável. Assim, realizou-se a triangulação para a validação dos resultados encontrados (CRESWELL, 2010).

\section{DISCUSSÕES E RESULTADOS}

Os negócios do Walmart começaram a ser realizados no estado do Arkansas (EUA) em 1962 e atualmente estão sendo praticados em 15 diferentes países sob o foco de multimarcas. No Brasil, suas atividades começaram a ser desenvolvidas no interior de São Paulo em 1995, com a marca Walmart Supercenter, e, ao longo de um processo de expansão, a empresa entrou no mercado nordestino em 2004, a partir da aquisição da rede Bompreço de supermercados, agregando ao grupo mais 118 lojas e três centros de distribuição na região. Após quase duas décadas de atuação no mercado brasileiro, a empresa indica que vem buscando atender a diferentes perfis de consumidores (WALMART BRASIL, 2010a).

Apesar de conhecido em contexto global, o Walmart possui um destaque e uma imagem no mercado questionável por muitos- a de uma empresa socioambientalmente responsável. Segundo depoimento do Diretor Nacional de Comunicação do Walmart, a preocupação com o problema do aquecimento global e a busca pelo atendimento da missão empresarial - vender por menos para as pessoas viverem melhor - foram estímulos para o início das práticas responsáveis ao entender que, para uma melhor qualidade de vida dos seus consumidores, a empresa deve direcionar suas atividades a um desenvolvimento sustentável, transformando essa visão em um dos seus pilares estratégicos (Tabela 1). 


\begin{tabular}{|c|c|c|c|c|}
\hline & \multicolumn{4}{|c|}{ Tabela 1: Pilares estratégicos do Walmart Brasil } \\
\hline & \multicolumn{4}{|c|}{ Ano de Exercício analisado } \\
\hline & 2007 & 2008 & 2009 & 2010 \\
\hline \multirow{6}{*}{$\begin{array}{l}\text { Estratégias } \\
\text { Corporativas }\end{array}$} & $\begin{array}{l}\text { Ser a melhor opção de } \\
\text { experiência de compra } \\
\text { para o consumidor }\end{array}$ & $\begin{array}{l}\text { Ser a melhor opção } \\
\text { de experiência de } \\
\text { compra para o consu- } \\
\text { midor }\end{array}$ & $\begin{array}{l}\text { Ser a melhor experiên- } \\
\text { cia de compras, com } \\
\text { preços imbatíveis }\end{array}$ & $\begin{array}{l}\text { Crescimento } \\
\text { acelerado }\end{array}$ \\
\hline & $\begin{array}{l}\text { Focar na redução de } \\
\text { custos e na produtivi- } \\
\text { dade }\end{array}$ & $\begin{array}{l}\text { Foco em custo baixo e } \\
\text { preço baixo }\end{array}$ & $\begin{array}{l}\text { Foco na redução de } \\
\text { custos e no aumento } \\
\text { da produtividade }\end{array}$ & $\begin{array}{l}\text { Melhora na ren- } \\
\text { tabilidade }\end{array}$ \\
\hline & $\begin{array}{l}\text { Crescer de forma lu- } \\
\text { crativa e contínua }\end{array}$ & $\begin{array}{l}\text { Crescer de forma lu- } \\
\text { crativa e contínua }\end{array}$ & $\begin{array}{l}\text { Crescer de forma lu- } \\
\text { crativa e contínua }\end{array}$ & $\begin{array}{l}\text { Ser líder em sus- } \\
\text { tentabilidade e } \\
\text { responsabilida- } \\
\text { de social corpo- } \\
\text { rativa }\end{array}$ \\
\hline & $\begin{array}{l}\text { Ter funcionários enga- } \\
\text { jados e motivados }\end{array}$ & $\begin{array}{l}\text { Engajar e motivar os } \\
\text { funcionários }\end{array}$ & $\begin{array}{l}\text { Engajar e desenvolver } \\
\text { os funcionários }\end{array}$ & \\
\hline & $\begin{array}{l}\text { Ser líder em responsa- } \\
\text { bilidade social e am- } \\
\text { biental }\end{array}$ & $\begin{array}{l}\text { Liderar em sustenta- } \\
\text { bilidade }\end{array}$ & $\begin{array}{l}\text { Ser líder em sustenta- } \\
\text { bilidade e responsabi- } \\
\text { lidade social }\end{array}$ & \\
\hline & $\begin{array}{l}\text { Ser o melhor canal en- } \\
\text { tre o fornecedor e o } \\
\text { consumidor }\end{array}$ & $\begin{array}{l}\text { Ser o melhor canal } \\
\text { entre o fornecedor e } \\
\text { o consumidor }\end{array}$ & $\begin{array}{l}\text { Ser o melhor canal en- } \\
\text { tre o fornecedor e o } \\
\text { consumidor }\end{array}$ & \\
\hline
\end{tabular}

Fonte: Walmart Brasil (2008, p. 22; 2009, p. 17; 2010b, p. 13; 2011, p. 13).

Como se pôde observar anteriormente, ao longo dos anos, a empresa demonstrou preocupação com a sustentabilidade ao incorporar essa ideia às suas estratégias, o que pode ser visto, mesmo que essa preocupação tenha assumido um aspecto de proporcionar à organização um espaço diferencial no mercado, pela ideia contínua de liderança. Liderar não quer dizer que há atuação responsável, razão pela qual é necessário observar quais são as outras ações desenvolvidas pela empresa para identificar se esta, de fato, atua positivamente na área. Assim, considerando o modelo de Michaelis (2003) apresentado no referencial teórico deste artigo, busca-se, a seguir, identificar quais as principais contribuições da empresa para o consumo sustentável no setor, bem como discutir como ocorre o seu relacionamento com a mídia local.

\subsection{Consumo sustentável no varejo de supermercados: a atuação do Hiper Bompreço}

Considerando a necessidade de analisar diferentes interações sociais para atingir ao objetivo proposto, identificou-se que os dez stakeholders mais relevantes para o atendimento das necessidades sociais e ambientais do Walmart Brasil são, em ordem de prioridade: funcionários; clientes; fornecedores; governo municipal; governo estadual; governo federal; mídia; organizações não governamentais; comunidade; e sindicatos e associações de classe. Segundo o então presidente do Walmart Brasil, Marcos Samaha, o engajamento dos atores na rede de stakeholders da empresa envolve "busca por mudanças nos padrões de consumo e produção e uso de recursos naturais", visando à construção de um futuro mais justo (SILVA; SANTOS, 2011; WALMART BRASIL, 2011, p.10).

Com base na discussão realizada sobre o consumo sustentável e nas categorias, nos critérios e nos parâmetros articulados por Silva (2011), torna-se possível identificar a contribuição e atuação da empresa em sua rede de influências. Quanto ao desenvolvimento de novas práticas e tecnologias, de acordo com as informações levantadas ao longo da pesquisa em relação à variável eco-eficiência, identificou-se não haver um processo de reutilização de materiais bem-articulado na empresa nem uma certificação que seja acreditada interna ou externamente à empresa. Para a gerente entrevista- 
da, o que existe é o Selo Clube do Produtor, utilizado de forma meramente ilustrativa para classificação de orgânicos, o que gera pouca atuação e prejudica suas ações para o consumo sustentável.

Para que o estímulo à reciclagem ocorra, um conjunto de parceiras é realizado pela empresa no sentido de melhorar o escoamento e a entrega dos materiais e, assim, reduzir o máximo possível o impacto sobre o meio ambiente. Tal prática demonstra que a empresa consegue se articular positivamente e busca minimizar seu impacto na sociedade. Essa prática é internalizada pelos funcionários, os quais, durante o processo de observação no Hiper Bompreço de Casa Forte, indicaram a efetivação do processo de reciclagem que envolve a separação, a prensa, a criação de fardos e a entrega para os destinos mais corretos. Essa visão inicial demonstra alguns relacionamentos que vão sendo criados para o desenvolvimento das atividades da empresa no contexto local.

Em Recife, nenhum Hiper Bompreço apresenta característica de loja eco-eficiente tendo em vista que as atuais são lojas preexistentes resultantes do processo de aquisição da marca Bompreço no nordeste pelo Walmart Brasil. Isso prejudica a prática responsável da empresa, já que essa variável contribui de forma desfavorável para as ações desenvolvidas. Mesmo assim, existe uma alternativa, pois, segundo o ex-presidente Hector Núñez, nos locais onde novas lojas não são previstas, a inserção de aspectos de eco-eficiência ocorrerá durante as reformas realizadas, para reduzir o impacto ambiental (WALMART BRASIL, 2009). Na região nordeste, aos poucos a empresa tem inserido lojas eco-eficientes, o que continuamente recebe destaque na mídia e, de maneira indireta, pode influenciar a visão do consumidor.

Outra variável analisada, práticas próprias de consumo, relacionada com a gestão da água, da energia e dos resíduos sólidos, demonstra que está havendo uma maior preocupação por parte da empresa, pois, de acordo com a gerente entrevistada, são criados planos que vão gradativamente sendo colocados em prática para reduzir o desperdício e promover melhores condições para o meio ambiente. No entanto, ao analisar a variável gestão de transportes, a preocupação com essa prática de consumo leva o Walmart a observar seu impacto ambiental atrelado, por exemplo, com a emissão de gases de efeito estufa.

Já quanto aos aspectos relacionados à mudança nos incentivos econômicos, que, segundo Michaelis (2003), não se refere apenas a influências do governo, mas também às interações no setor econômico, percebeu-se um direcionamento da empresa para um comportamento ativo no setor, já que "foi a primeira empresa de varejo a apoiar a campanha Saco é um Saco, realizada pelo Ministério do Meio ambiente com o objetivo de conscientizar as pessoas de que a sacola pode ser útil, mas nem sempre é necessária, e de que existem formas de otimizar o uso" (WALMART BRASIL, 2009, p. 37). Como observado no mapeamento dos stakeholders realizado por Silva e Santos (2011), continuamente o Walmart Brasil interage com o governo, seja no contexto nacional, estadual ou municipal.

No que se refere aos fornecedores, segundo a empresa "a mesma adota um modelo de estímulo mútuo e crescimento integrado, visando consolidar uma rede de negócios sustentáveis dos pontos de vista econômico, social e ambiental" (WALMART BRASIL, 2009, p. 53). Isso é visualizado nas suas relações comerciais, pois a empresa possui uma política de ética na cadeia de suprimentos, aplicada a todos os fornecedores. Como exemplo, pode-se citar o programa Clube de Produtores, que visa integrar pequenos fornecedores de produtos agrícolas. Tal ação, entretanto, não gera o destaque esperado desses produtos no Recife, sendo identificado um destaque tênue no Hiper Bompreço Boa Viagem e um destaque mais elevado na região sudeste.

Além dessa, chama-se atenção para o programa Sustentabilidade de Ponta a Ponta, que estimula a mudança em determinados produtos oferecidos na empresa. Tal aspecto demonstra outras relações que são criadas pela empresa em suas atividades no mercado, as quais não necessariamente seguem de fato as condições de eco-eficiência até então apresentadas. 
No que tange à variável processo decisório responsável, entende-se que todas as decisões que são tomadas interferem na dinâmica da empresa. Todavia, quando essas ações se apresentam responsáveis ou voltadas para uma perspectiva social e ambiental, a contribuição empresarial é vista como positiva (WBCSD, 2008). Já quanto à análise da procedência do produto a ser vendido, a edição de escolha da empresa impacta diretamente nos produtos oferecidos em loja e facilita o estímulo ao consumo consciente, por exemplo (WBCSD, 2008).

A última vertente a ser analisada, a dimensão mudança cultural na rede de influências do modelo de Michaelis (2003), contribui mais positivamente para a efetivação do consumo sustentável no varejo de supermercados de acordo com as práticas da empresa, pois indica contribuições mais impactantes na localidade. Identificou-se o estímulo a uma cidadania corporativa considerando as questões econômica, legal, ética e discricionária definidas pelo modelo de Carroll (1998), além de uma série de ações desenvolvidas para tornar claro aos funcionários o conceito de sustentabilidade e disseminar formas de aplicá-lo na prática, dentro e fora de seu ambiente, o que contribui para a disseminação das práticas empresariais.

No que tange ao composto de marketing responsável, no Walmart Brasil, percebem-se estratégias relacionadas a formatos de loja, merchandising e precificação (WALMART BRASIL, 2011). Foram identificados os quatro elementos fundamentais a essa atividade empresarial, de forma elementar ao longo do ano e com maior destaque no chamado Mês da Terra, quando ocorre uma ação de marketing no mês de julho que tem como tema a sustentabilidade.

No que se refere à variável diálogo com stakeholders, verifica-se uma efetiva relação da empresa com os três considerados nesse momento (mídia, comunidade e organizações não governamentais), o que favorece sua contribuição ao consumo sustentável no setor. O maior destaque ocorre quanto à relação com a comunidade no que se refere ao programa de desenvolvimento local integrado - Bombando Cidadania.

Além de todas essas interações, percebe-se a necessidade de relação da empresa com instituições não governamentais (MONT; PLEPYS, 2007), já que estas podem facilitar o reconhecimento de ações e discursos de uma organização por toda a sociedade, o que pode ser desenvolvido de forma positiva ou não. Em contato com alguns catadores durante uma observação, questionou-se sobre a efetividade de atuação da empresa, sendo identificada uma atuação ativa desta empresa com relação a essa parceria, já que todo o material que estivera disponível naquelas estações de reciclagem e fora da empresa é direcionado diretamente para a cooperativa Pró-Recife. Tal fato indica que o Walmart Brasil desenvolve parceria e se relaciona positivamente com as referidas instituições.

Além disso, dentro dessa ideia de diálogo, percebe-se a interação com a mídia, o que receberá maior destaque em seguida. A partir das considerações até então realizadas, observa-se que há um direcionamento da empresa a desenvolver parcerias sob a perspectiva do consumo sustentável. Assim sendo, percebe-se que, apesar de não ter aspectos tão favoráveis na dimensão de novas práticas e tecnologias, a empresa busca estimular com seu comportamento a efetivação de um consumo sustentável no varejo de supermercados.

\subsection{A ação midiática e comunicativa na visão da empresa}

Para que todas as relações apresentadas anteriormente sejam conhecidas por uma audiência ampliada, o processo comunicacional pode ser a melhor ferramenta utilizada a fim de elaborar um discurso junto à sociedade. Isso pode ocorrer tanto pela atuação individual por parte da empresa, com toda a sua prática mercadológica, quanto pela utilização das definições que são elaboradas e disseminadas pela mídia. Segundo Rossetti e Giacomini Filho (2010, p. 168), essas relações fazem parte 
de um jogo, nesse caso positivo, na busca por uma prática favorável comunicacional pública, o que confere "comprometimento das partes envolvidas, categorizando o consumo sustentável como bem socialmente defensável e aos que participam interação com uma imagem responsável".

A partir das ações desenvolvidas pelo Instituto Walmart, o diálogo com os stakeholders pode ser visualizado de forma singular na relação com a mídia. Parte-se do argumento de que, a partir de um bom relacionamento com a mídia, seja por meio de parcerias ou de estímulos às práticas que estão sendo desenvolvidos, é mais fácil realizar ações voltadas para um consumo sustentável. Tal fato está relacionado com o trabalho desenvolvido em seu website e em diversas mídias sociais que buscam disseminar as informações da empresa. Continuamente, o Walmart Brasil precisa interagir com a mídia seja para disseminar suas práticas ou para responder a estímulos externos, assumindo, assim, uma atuação positiva no mercado.

Como apresentado na seção anterior, enquanto sétimo ator em ordem de importância, a mídia (imprensa) ou os meios de comunicação (rádios, revistas, jornais, televisão e canais de notícias na internet) recebem enfoque como canais de relacionamento que proporcionam a ideia de transparência da empresa com a sociedade, a partir de: comunicados e coletivas para a imprensa, envio de releases e notas para a imprensa, entrevistas sobre assuntos relevantes da empresa e atendimento diário às solicitações de veículos de comunicação (WALMART BRASIL, 2011). Assim, esse ator contribui positivamente para o processo de conscientização de consumidores e outros atores na sociedade em busca do alcance da sustentabilidade.

Como apresentado no Relatório de Sustentabilidade 2011, os meios de comunicação são responsáveis por apresentar as iniciativas de sustentabilidade que facilitam os programas da empresa, como é o caso do "Sustentabilidade de Ponta a Ponta". Dessa forma, a mídia torna-se ativa no processo de interação com o Walmart Brasil, seja por meio de ações positivas ou, quando conveniente, denunciando possíveis desrespeitos identificados. Essa ideia vai de encontro ao que apresenta a pesquisa de Santos (2006), na qual as empresas ou indústrias não são mencionadas e verificadas na mídia segundo análise da autora, o que sugere pouca interferência no imaginário social da empresa como central para uma mudança. No caso da presente pesquisa, isso é completamente diferente, pois o peso da marca e do nome da empresa levam as pessoas a compreenderem a necessidade de mudança.

Tal fato é observado direta ou indiretamente por meio do poder de persuasão que a mídia tem sobre a construção de um posicionamento da população como um todo. Em 2011, por exemplo, após a aprovação de uma lei, publicada no Diário Oficial ${ }^{3}$, sobre a necessidade de exclusividade de caixa de atendimento para pessoas com sacolas retornáveis, a mídia desenvolveu papel importante em Pernambuco, comunicando a população sobre um direito seu e lembrando a empresa, indiretamente, da existência de fiscalização, pois, caso a lei não seja cumprida, o fato será disseminado em grande escala. Esse acontecimento demonstra a importância de intenso diálogo com a mídia. No Hiper Bompreço, isso é identificado na entrevista com a Gerente Regional (do nordeste) de comunicação:

Se a três, quatro anos a gente provocava os formadores de opinião, os jornais, os sites, os veículos de comunicação, a darem espaço, a divulgarem projetos [...] tentando fazer o assunto sustentabilidade ser de interesse deles, com pautas, projetos, isso não ocorre mais. Hoje, eu sou demandada por eles por esses assuntos. Por quê? Porque já é uma preocupação do consumidor, do leitor, do internauta, do telespectador [...].

Como se pode observar no trecho transcrito, há uma interação ativa entre a empresa e a mídia que recebe e gera pressão mútua, melhorando, assim, a disseminação dos aspectos

${ }^{3}$ Lei n. - 17.773/2011, que obriga os hipermercados, supermercados, mercados e estabelecimentos congêneres a disponibilizar caixa preferencial aos consumidores que utilizarem sacolas retornáveis. 
responsáveis. Com tais considerações, entende-se que a variável analisada pode contribuir e está contribuindo positivamente para a busca por um consumo sustentável, à medida que desenvolve ações para a disseminação de informações e educação dos consumidores sobre sustentabilidade, mesmo que a empresa ainda não tenha se adequado às necessidades da nova lei.

Esse fato mostra que a empresa se apresentou como reativa na introdução de uma iniciativa que tem o potencial de estimular um novo comportamento dos consumidores, pois já poderia estar trabalhando dessa maneira anteriormente à publicação da lei. Apesar disso, existem outras formas de divulgar informações, como os relatórios de sustentabilidade, que, segundo Kruglianskas, Aligreri e Aligreri (2009), demonstram o caráter transparente da empresa à medida que esta realiza a prática de uma comunicação responsável. Esses relatórios sociais servem para ampliar o conhecimento e reconhecimento da empresa por parte de seus consumidores e de todos os outros atores que estejam atuando no varejo de supermercados, já que apresentam as ações que estão sendo desenvolvidas.

Entende-se, assim, que a utilização do relatório social como aspecto comunicacional de suas ações empresariais responsáveis facilita a disseminação de uma nova visão junto aos atores de sua rede. Nesse sentido, percebe-se que o Walmart Brasil possui uma contribuição efetiva para a mudança de perspectiva dos envolvidos com a empresa, tendo em vista que nos últimos anos ocorreu uma contínua apresentação desses relatórios para a sociedade. Construído a partir dos indicadores do Global Reporting Iniciative (GRI), os relatórios sociais do Walmart Brasil apresentam informações sobre a maior parte das ações desenvolvidas, tendo a cada ano um novo formato de acordo com as necessidades de seus stakeholders. Percebe-se, então, que essa comunicação pode facilitar a mudança no comportamento de diversos atores em meio às diferentes transformações verificadas.

No entanto, apesar de bem-organizados e com um conjunto de informações que estão de acordo com o que é desenvolvido na empresa, os relatórios sociais são pouco conhecidos pelos consumidores de loja, fato que poderia ser modificado com ações alinhadas àquelas referentes ao marketing responsável praticado pelo Walmart Brasil. Assim, entende-se que está no marketing responsável o ponto-chave para a disseminação das práticas desenvolvidas pela empresa tanto para com seus consumidores quanto para com todos os atores que se relacionam com a empresa, contribuindo para a efetivação do consumo sustentável e melhorando a compreensão acerca da audiência de suas práticas.

Tal processo de comunicação responsável, se for produzido de forma insuficiente ou buscando suprimir ações negativas desenvolvidas pelas empresas, como destaca Santos (2006, p. 6), pode ser entendido como "ingrediente que constitui e interfere nas bases da produção simbólica, tornando-se assim, a mídia, dispositivo legitimador deste jogo de representações, em que as idiossincrasias da agenda pública simplesmente não são explicitadas". Com a análise dos links encontrados em notícias, reportagens ou depoimentos sobre a empresa, identificaram-se constantes apresentações de ações responsáveis (como a entrega de mudas), divulgação de assistência (como a ajuda a desabrigados e a inserção de diferentes profissionais no mercado de trabalho) e de promoções e valorizações da empresa.

Não se identificaram ações massificadas ou divulgações amplas acerca de algo positivo sobre a empresa, bem como nada que denegrisse sua imagem de forma impactante. A existência de alguns blogs indicando descontentamento com o mau atendimento em lojas e o contínuo estímulo à prática do consumo em si em função das ações promocionais que são apresentadas dificultam a compreensão sobre a real relação entre as partes analisadas. Sabe-se que a empresa está sempre em busca de apresentar uma imagem positiva e desenvolver novas ações comunicativas, mas como a mídia está atuando de fato? A resposta a esse questionamento fica em aberto, considerando que o que foi analisado não conferiu embasamento efetivo sobre o que pode ser desenvolvido. No entanto, existem indicativos, como declara a Gerente entrevistada: 
Hoje, existem cadernos, colunas, programas de rádio, programas de TV, sites específicos do assunto sustentabilidade, onde naturalmente, eu já tenho um bom espaço, para falar do assunto...

Toda semana, todo mês, pra ser mais honesta, tem algum Caderno Especial, em um jornal do nordeste, do Brasil, sobre sustentabilidade. Então, assim, hoje a relação com a imprensa, quando o assunto é sustentabilidade, ela está muito mais fácil. Primeiro, que o jornalista já sabe do que você tá falando e, segundo, porque ele tem mais espaço pra dá porque o leitor tá mais interessado em saber.

A partir dessa visão, considera-se que o relacionamento ocorre por meio de uma atuação responsável quando as ações desenvolvidas sobre sustentabilidade estão sendo trabalhadas de forma positiva tanto pela empresa quanto pela mídia aqui analisada. Apesar disso, nada impede que se considere a possibilidade de um jogo de mercado, já que muito do que foi analisado em determinados momentos era um conteúdo presente no site da empresa. Ainda assim, com esta perspectiva e, algumas ressalvas, considera-se que há um direcionamento positivo por parte da empresa para o consumo sustentável, principalmente na relação da díade analisada, já que as discussões buscam trazer uma visão concisa e prática das relações e movimentações que podem ser realizadas no varejo de supermercados.

\section{CONSIDERAÇÕES FINAIS}

De acordo com a dinâmica social que vem sendo verificada nos últimos anos, é cada vez mais necessário que as empresas busquem se adequar a um novo contexto setorial, o que ocorre a partir da construção de novas relações em sua rede de influência, como indica a abordagem do consumo sustentável. A mudança de foco da sociedade de consumo para questões coletivas voltadas ao desenvolvimento sustentável apresenta-se extremamente importante, já que os níveis atuais de produção e consumo não serão suportados por muito tempo tendo em vista a potencial escassez dos recursos naturais (ASSADOURIAN, 2010). Assim, o processo de parceria e cooperação entre os atores sociais encontra-se estimulado.

Como sugere Silva (2012), a percepção coletiva sobre a necessidade de mudança precisa ser trabalhada de modo tal que a prática de um consumo sustentável, a partir das diferentes interações sociais, possa ser efetivada. Essa mudança de percepção está alinhada ao processo comunicacional entre os atores.

Para a presente discussão, analisou-se apenas a díade empresa-mídia - o que não implica uma pesquisa simples, já que esses atores possuem papel de influência em toda a sociedade. A partir das reflexões realizadas, foi possível atender ao objetivo proposto, tendo em vista que as relações apresentadas demonstram a atuação desses atores.

Entende-se que há, no Walmart Brasil, mesmo com as muitas desconfianças sociais sobre a conduta da empresa, um direcionamento, ainda que muitas vezes indireto, para a construção de um padrão sustentável de consumo no varejo de supermercados por meio de suas práticas empresariais responsáveis. Esse fato indica que o Walmart Brasil, especificamente quanto ao Hiper Bompreço, encontra-se envolvido com sua rede de influências, contribuindo positivamente para a dinâmica do setor. A partir do reconhecimento evolutivo das ações desenvolvidas, na medida em que estas foram incorporadas como um dos pilares estratégicos, e das relações e parcerias que são e estão sendo desenvolvidas pela empresa, tornou-se possível evidenciar as suas contribuições.

Apesar de a discussão ter sido voltada para o contexto empresarial, o objetivo consistiu em discorrer sobre as interações e os possíveis impactos de diferentes stakeholders sobre a sociedade. Sabese que a mídia assume papel fundamental na construção de opiniões sociais e que as empresas conse- 
guem, por meio de sua prática mercadológica, informar e educar o consumidor sobre produtos, serviços e conceitos que lhe são ofertados, de modo que, à medida que essas ações convergem sobre um mesmo prisma e apresentam influência direta sobre a sociedade, torna-se possível identificar as ações realizadas nesse quesito. Isso é possível, segundo Rossetti e Giacomini Filho (2010, p. 168), pois "a comunicação interpessoal ou grupal envolvendo o consumo sustentável forma uma base consensual que alimenta discursos massivos, que por sua vez contribuem com uma nova base consensual".

Diante de todas as discussões, com a ressalva da possibilidade de jogo de mercado por parte da empresa, identifica-se, para as relações aqui analisadas, uma atuação responsável quanto às interações do Walmart Brasil, tendo em vista a marca Hiper Bompreço em Recife, o que contribui positivamente para a busca pela efetivação do consumo sustentável no varejo de supermercados em Pernambuco. Uma das limitações da pesquisa é o fato de a análise ter sido realizada sob a ótica da empresa, o que pode enviesar o entendimento do fenômeno, e a dificuldade em identificar notícias, reportagens e depoimentos de acordo com a necessidade de pesquisa. Além disso, foi preciso suprimir muitas informações relevantes sobre as relações e práticas da empresa em detrimento do escopo de análise. Assim, surgem implicações gerenciais, já que, ao identificar quais são os hiatos existentes em suas ações desenvolvidas, as empresas podem assumir o seu papel de responsabilidade e modificar sua forma de atuação e seu comportamento no mercado.

Na perspectiva acadêmica, os estudos podem ser continuados com pesquisas sobre a prática efetiva da mídia, seja por meio de comunicação tradicional ou por meio das novas mídias sociais, tendo em vista os motivos para focar especificamente aspectos voltados para a sustentabilidade. Seria interessante, também, uma análise sobre as práticas sustentáveis que atentasse para outros atores da rede de influência dessa e de outras empresas, o que facilitaria a evolução das discussões sobre a temática. Assim, ressalta-se que a principal contribuição desta pesquisa consiste em destacar que, em meio a um conjunto de interações sociais que são necessárias para o consumo sustentável, a relação empresa-mídia apresenta-se como imprescindível para o processo de construção da opinião coletiva.

\section{REFERÊNCIAS}

ASSADOURIAN, E. Ascensão e queda das culturas de consumo. In: WORLDWATCH INSTITUTE. Estado do Mundo, 2010: estado do consumo e o consumo sustentável. Salvador: Uma Ed., 2010.

BARDIN, L. Análise de Conteúdo. 4ae ed. Lisboa: Edições 70, 2009.

CARROLL, A. B. The Four Faces to Corporate Citizenship. Business and Society Review. p. 1-7. 1998.

CRESWELL, J. W. Projeto de pesquisa: métodos qualitativo, quantitativo e misto. 3. ed. Porto Alegre: Artmed/Bookman, 2010.

ELKINGTON, J. Canibais com garfo e faca. São Paulo: Makroon Books, 2001.
FOLADORI, G. Por uma sustentabilidad alternativa. Uruguai: Colección Cabichui, 2005.

GOLDENBERG, M. A arte de pesquisar: como fazer pesquisa qualitativa em ciências sociais. Rio de Janeiro: Record, 2009.

GUNTHER, M. The Green Machine. 2006. Fortune Magazine. Disponível em: <http:// money.cnn.com/magazines/fortune/fortune archive/2006/08/07/8382593/> Acesso em: mar. 2012.

JACKSON, T. Negotiating Sustainable Consumption: A review of the consumption debate and its policy implications. Energy \& Environment. (15), p.1027-1051. 2004.

\section{Sustainable Consumption. In:}

ATKINSON, Giles; DIETZ, Simon; NEUMAYER, Eric (editors). Handbook of Sustainable Development. Edward Elgar Publishing, 2007. 
KRUGLIANSKAS, I.; ALIGLERI, L.; ALIGLERI, L. A. Gestão socioambiental: responsabilidade e sustentabilidade do negócio. São Paulo: Atlas, 2009.

LIPOVETSKY, G. A felicidade paradoxal: ensaio sobre a sociedade de hiperconsumo. São Paulo: Companhia das Letras, 2007.

MÁLOVICS, G.; CSIGÉNÉ, N. N.; KRAUS, S. The role of corporate social responsibility in strong sustainability. The Journal of Socio-Economics. 37, p.907-918. 2008.

MENDONÇA, R. F. A mídia e a transformação da realidade. Comunicação \& Política. 24, (4). p. 07-37. 2006.

MICHAELIS, L. Sustainable consumption and production. In: DODDS, F.; MIDDLETON, T. Earth Summit 2002: A new deal. Earthscan Publications Ltd. 2000.

The role of business in sustainable consumption. Journal of Cleaner Production, 11, 2003.

MONT, O.; PLEPYS, A. Sustainable consumption progress: should we be proud or alarmed? Journal Cleaner Production. 16, p.531-537. 2007.

OLIVEIRA, M. M. Como fazer pesquisa qualitativa. Recife: Ed. Bagaço, 2005.

REISCH, L.; SPASH, C. L.; BIETZ, S. Sustainable Consumption and Mass Communication: A German experiment. Socio-Economics and the Environment in Discussion: CSIRO working paper series. 2008.

ROSSETTI, R.; GIACOMINI FILHO, G. Comunicação, consenso social e consumo sustentável. Comunicação, mídia e consumo. 7, (18). p. 153-169. 2010.

SACHS, I. Rumo à ecossocioeconomia: Teoria e prática do desenvolvimento. São Paulo: Cortez, 2007.

SANTOS, L. L. Comunicação e consumo sustentável: das entrelinhas do capitalismo leve ao enquadramento da sustentabilidade na mídia. Revista Fronteiras - Estudos midiáticos. (3), p. 223-233. 2005.

- O enquadramento midiático da sustentabilidade e o papel da mídia na assimilação social do consumo sustentável. In Anais... XXIX Congresso Brasileiro de Ciência da Comunicação. Universidade de Brasília: Brasília, 2006.

SANTOS, T. C.; LEITE, A. P. R.; TACCONI, M. F. F. S.; ALEXANDRE, M. L. Movimento do Consumo Consciente: do Cidadão Consumidor ao Consumidor Cidadão? In Anais... Encontro de Administração Pública e Governança - EnAPG. Salvador, 2008.

SANTOS, T. D. F. Mudanças de paradigmas e o papel da mídia: a comunicação como ferramenta do processo de transição. In Anais... I Encontro de História da Mídia da Região Norte. Universidade Federal de Tocantins: Palmas, 2010.

SILVA, M. E. A contribuição de práticas empresariais responsáveis para o consumo sustentável no varejo de supermercados: $O$ caso Walmart Brasil. 137p. Dissertação (Mestrado em Administração) - Programa de Pós-Graduação em Administração (PROPAD). Universidade Federal de Pernambuco, Recife: 2011.

- Consumo Sustentável: A Articulação de um constructo sob a perspectiva do desenvolvimento sustentável. Revista Eletrônica de Ciências Administrativas (RECADM). 11, (2). 2012.

SILVA, M. E.; GÓMEZ, C. R. P. Consumo Consciente: O papel contributivo da educação. Reuna (Belo Horizonte), 15, n.3, p.43-54. 2010. SILVA, M. E.; SANTOS, C. F. O. S. A estratégia socioambiental do Walmart Brasil: Entendendo suas ações e as interações em sua rede de stakeholders. In Anais... XXXV Encontro da ANPAD - EnANPAD, 2011. 
SOLOMON, M. R. Comportamento do Consumidor. Bookman: Porto Alegre. 2011.

TUKKER, A.; EMMERT, S.; CHARTER, M.; VEZZOLI, C.; STO, E.; ANDERSEN, M. M.; GEERKEN, T.; TISCHNER, U.; LAHLOU, S. Fostering change of sustainable consumption and production: an evidence based view. Journal of cleaner production, 16. 2008.

WALMART BRASIL. Institucional Walmart. 2010a. Disponível em: <http://www. walmartbrasil.com.br/institucional/nomundo. aspx>. Acesso em: dez. 2011.

. Relatório de sustentabilidade 2008 (Exercício 2007). 2008. Disponível em: $<$ http://www.walmartsustentabilidade.com. br/_pdf/relatorios/walmart-relatorio-desustentabilidade-2008.pdf > Acesso em: dez. 2011.

Relatório de sustentabilidade 2009 (Exercício 2008). 2009. Disponível em: <http://www.walmartsustentabilidade.com. br/_pdf/relatorios/walmart-relatorio-desustentabilidade-2009.pdf> Acesso em: dez. 2011.

Relatório de sustentabilidade 2010 (Exercício 2009). 2010b. Disponível em: <http://www.walmartsustentabilidade.com. br/_pdf/relatorios/walmart-relatorio-desustentabilidade-2010.pdf> Acesso em: dez. 2011.

Relatório de sustentabilidade 2011 (Exercício 2010). 2011. Disponível em: <http:// www.walmartsustentabilidade.com.br/ relatorio-online/downloads/Walmart_RA10_ pt.pdf> Acesso em: dez. 2011.

WBCSD (World Business Council for Sustainable Development). Sustainable Consumption: Facts e Tends - From a business perspective. 2008. Disponível em: <http://www.wbcsd.org/ DocRoot/19Xwhv7X5V8cDIHbHC3G/WBCSD_ Sustainable_Consumption_web.pdf $>$. Acesso em: mai. 2011.
WCED (World Commission on Environment and Development). Report our common future. Genebra, 1987. Disponível em: <http://www. un-documents.net/wced-ocf.htm.>. Acesso em: 2012. 